Article

\title{
Histological and Comparative Transcriptome Analyses Provide Insights into Small Intestine Health in Diarrheal Piglets after Infection with Clostridium Perfringens Type C
}

\author{
Zunqiang Yan ${ }^{1}{ }^{10}$, Lijuan Cai ${ }^{1}$, Xiaoyu Huang ${ }^{1}$, Wenyang Sun ${ }^{1}$, Shouhu Li ${ }^{2}$, Pengfei Wang ${ }^{1}$, \\ Qiaoli Yang ${ }^{1}$, Tiantuan Jiang ${ }^{3}$ and Shuangbao Gun ${ }^{1,3, *}$ \\ 1 College of Animal Science and Technology, Gansu Agricultural University, Lanzhou 730070, China; \\ yanzunqiang@163.com (Z.Y.); Cailj214@163.com (L.C.); huanghxy100@163.com (X.H.); \\ sun_china@outlook.com (W.S.); wangpf815@163.com (P.W.); yangq10112@163.com (Q.Y.) \\ 2 College of Veterinary Medicine, Gansu Agricultural University, Lanzhou 730070, China; \\ lishouhu88@163.com \\ 3 Gansu Research Center for Swine Production Engineering and Technology, Lanzhou 730070, China; \\ jiangtt@gsau.edu.cn \\ * Correspondence: gunsbao056@126.com; Tel.: +86-931-763-1804
}

Received: 27 April 2019; Accepted: 21 May 2019; Published: 23 May 2019

check for updates

Simple Summary: Clostridium perfringens (C. perfringens), formerly called Clostridium welchii, is a spore-forming pathogenic bacterium. C. perfringens type $C$ can produce fatal toxins, which are absorbed by the small intestine into the body causing diarrhea in humans and animals, especially piglets. Each year, diarrhea induced by this pathogen causes significant economic loss to the pig industry worldwide. Nevertheless, the regulatory mechanisms of the duodenum, jejunum, and ileum in piglets challenged by $C$. perfringens type $C$ are poorly understood. This study aimed to identify pathological changes and genes associated with the small intestine in piglets after infection with C. perfringens type C. RNA-Sequencing (RNA-Seq), enzyme-linked immunosorbent assay (ELISA), and hematoxylin \& eosin (H\&E) staining were used to analyze duodenal, jejunal, and ileal tissues. Our results showed that treated piglets were successfully infected with C. perfringens type C. These findings will help to elucidate the pathogenicity of piglets infected with this pathogen.

\begin{abstract}
C$. perfringens type $C$ can induce enteritis accompanied by diarrhea and annually causes significant economic losses to the global pig industry. The pathogenic mechanisms of $C$. perfringens type $C$ in pigs are still largely unknown. To investigate this, we challenged seven-day-old piglets with $C$. perfringens type $C$ to cause diarrhea. We performed hematoxylin \& eosin (H\&E) staining of the small intestine (including duodenum, jejunum, and ileum) and assessed gene expression in the ileal tissue. H\&E staining of the duodenum, jejunum, and ileum demonstrated inflammation and edema of the lamina propria and submucosa. A total of 2181 differentially expressed genes (DEGs) were obtained in ileal tissues. Kyoto encyclopedia of genes and genomes (KEGG) pathway analysis of DEGs indicated that the main pathways were enriched in the T cell receptor signaling pathway, NF-kappa B signaling pathway, and (tumor necrosis factor) TNF signaling pathway. These results provide insights into the pathogenicity of $C$. perfringens type $C$ and improve our understanding of host-bacteria interactions.
\end{abstract}

Keywords: Ileum; Pig; Clostridium perfringens type C; Diarrhea 


\section{Introduction}

Clostridium perfringens is a gram-positive, anaerobic, spore-forming, and rod-shaped bacterium; it has five different subgroups (A, B, C, D, and E) in the present classification according to four major toxins, namely $\alpha(\mathrm{CPA}), \beta(\mathrm{CPB}), \varepsilon(\mathrm{ETX})$, and $\iota$ (ITX). Moreover, most strains of $C$. perfringens can produce several other toxins including beta 2 (CPB2) and enterotoxin (CPE) [1,2]. These toxins produced by $C$. perfringens are responsible for the process of several diseases, including necrotic enteritis, food poison, diarrhea, and enterogastritis [2,3]. Among the five subgroups, $C$. perfringens type $C$ produces at least two different major toxins ( $\alpha$ and $\beta$ toxin) and mainly causes enteritis characterized by diarrhea in animals, particularly piglets $[1,4]$. Piglets are susceptible to $C$. perfringens type $C$ and herd mortality rates surpass $30 \%$, which is a high cost to the pig industry $[5,6]$. In humans, C. perfringens type $C$ enters the gastrointestinal tract through the ingestion of contaminated meat (mainly pork) and leads to enteritis necroticans (also known as pigbel or Darmbrand) [4].

Recently, many papers regarding the pathogenesis of $C$. perfringens type $C$ have been published. These studies show that the intestinal tract is the first target organ in C. perfringens type $C$ infection and it is the jejunum and ileum in piglets that are mainly damaged by this bacterium $[7,8]$. Firstly, C. perfringens type $\mathrm{C}$ colonizes and multiplies in the intestinal tract; next, fatal bacterial toxins are absorbed by the intestinal tract and enter the circulatory system where they may induce a lethal effect [2,9]. RNA-Seq has been used to analyze intestinal transcriptome data from chickens with necrotic enteritis and the results indicate that $C$. perfringens type $\mathrm{A}$ infection affects the expression of some immunity genes (such as IL-4, TNFRSF13, IL-10, and IL-17B) to resist this bacterium [10,11]. Identification of functional immunity genes in piglets with $C$. perfringens type $C$ could help us further understand the pathogenesis of this infection in order to breed strains of diarrhea-resistant piglets. To date, transcriptome sequencing of the piglet small intestine infected with $C$. perfringens type $C$ has not taken place. Thus, it is necessary to explore the changes that take place in infected piglets and to screen for several immunity genes in an attempt to prevent and control diarrhea through breeding.

In this study, the duodena, jejuna, and ilea were collected and hematoxylin \& eosin (H\&E) stained for histological analysis. Subsequently, the presence of inflammatory cytokines was detected by enzyme-linked immunosorbent assay (ELISA). Next, we compared the transcriptome profile of mRNA in the ileal tissue of piglets, both non-infected and infected with C. perfringens type C, using RNA-Seq. In addition, some of the differentially expressed genes were selected for verification using real-time quantitative PCR (RT-qPCR). This research may accelerate the exploration of candidate genes that can respond to $C$. perfringens type $C$ infection in piglets. Furthermore, it also broadens the understanding of this bacteria-host interaction.

\section{Materials and Methods}

\subsection{Ethics Statement}

This study was approved by the Committee for Animal Ethics of the College of Animal Science and Technology, Gansu Agricultural University (approval number 2006-398). Experiments were conducted in accordance with the approved guidelines.

\subsection{Bacterium}

The C. perfringens type C strain (CVCC 2032) used in this study was purchased from China Veterinary Culture Collection Center (Beijing, China). Cultures were grown in bouillon medium (HopeBio, Qingdao, China) at $37^{\circ} \mathrm{C}$ for $16 \mathrm{~h}$ with agitation under anaerobic conditions. Cultures were obtained by centrifugation at $3000 \times g$ for $15 \mathrm{~min}$, washed three times with sterile PBS ( $\mathrm{pH}=7.2$ ), re-suspended in sterile PBS, and then enumerated depended on ten-fold serial dilutions experiment in yolk plate colony counting by our previous method [12]; density was adjusted to approximately $1 \times 10^{9} \mathrm{CFU} / \mathrm{mL}$ in preparation for oral challenge. 


\subsection{Animal Experiments}

Six seven-day-old piglets were randomly selected; they were healthy, had similar weights, and were not infected with C. perfringens, Escherichia coli, or Salmonella as detected with commercial ELISA kits (Jiancheng Bioengineering Institute, Nanjing, China) by our previously described methods [12]. In this study, these piglets had ad libitum access to antibiotic-free water and feed during the experimental period and each piglet was fed in an open single cage, to avoid cross-infection, at the animal testing ground of Gansu Agricultural University. Three piglets were randomly selected as the control group (CG), while the remaining three piglets were assigned to the treatment group (TG). Each piglet in TG was challenged by an oral gavage of $1 \mathrm{~mL} 1 \times 10^{9} \mathrm{CFU} / \mathrm{mL}$ medium once a day for five days, and each piglet in CG was treated with an equal volume of sterile PBS as previously described [12].

\subsection{Sample Collection}

During the experimental period, we collected blood via the anterior vena cava and fecal extracts from all six piglets at $0,1,3$, and 5 dpi (days post infection). Subsequently, the three piglets with C. perfringens type $C$ infection and three piglets without infection were euthanized and duodenal, jejunal and ileal samples were collected. These samples were placed into liquid nitrogen and stored at $-80^{\circ} \mathrm{C}$ until needed. The tissues were fixed in $10 \%$ neutral buffered formalin (NBF) for $24 \mathrm{~h}$ and then H\&E stained for histological analysis. Fecal extracts were re-suspended in sterile water and then secretory $\operatorname{IgA}(\operatorname{sIg} \mathrm{A})$ was quantified using an indirect ELISA assay kit (Jiangsu Kete Biological Technology Co., Ltd., Yancheng, China). Blood samples were left to coagulate naturally, and then centrifuged at $2000 \times g$ for $10 \mathrm{~min}$ at $4{ }^{\circ} \mathrm{C}$ to obtain the serum, which was used to detect the concentration of pro-inflammatory cytokines (IL-6 and TNF- $\alpha$ ) using ELISA assay kits (Jiangsu Kete Biological Technology Co., Ltd., Yancheng, China). All ELISA processes were conducted according to the manufacturer's instructions.

\subsection{Clinical Index Records}

Rectal temperature was detected daily after the challenge. In addition, all piglets were individually weighed each day. Finally, defecation times and fecal state were recorded. Fecal symptom traits $(0=$ normal, solid feces, $1=$ slight diarrhea, soft and loose feces, $2=$ moderate diarrhea, semi-liquid feces, 3 = severe diarrhea, liquid and unformed feces) were judged as previously described [13,14]. Piglets were considered to be diarrheic when the fecal score was at a level of two or greater.

\subsection{RNA Extraction and Analysis}

Total RNA from each sample of ileal tissue was extracted using TRIzol ${ }^{\mathrm{TM}}$ reagent (Invitrogen, Carlsbad, CA, USA). The concentration and purity of total RNA were detected using a NanoDrop-2000 spectrophotometer (Thermo Scientific, Waltham, MA, USA). An optical density $260 / 280$ ratio of 1.8 to 2.0 was treated as high quality total RNA. Then, the integrity of RNA was assessed by $1 \%$ formaldehyde denaturing gel electrophoresis and qualified total RNA was characterized by an approximate 2:1 ratio of $28 \mathrm{~S} / 18 \mathrm{~S}$. In addition, total RNA integrity was also assessed using the Bioanalyzer 2100 system (Agilent Technologies, CA, USA) for complementary (cDNA) library construction if RNA integrity number was more than eight.

\subsection{Library Preparation and Sequencing}

According to NEBNext ${ }^{\circledR}$ Ultra $^{\mathrm{TM}}$ RNA Library Prep Kit for Illumina ${ }^{\circledR}$ (NEB, Ipswich, MA, USA) instructions, total RNA ( $3 \mu \mathrm{g} /$ each ileum sample) was used as an input material for the sequencing library preparations. Firstly, poly-T oligo-attached magnetic beads were used to obtain mRNA from total RNA. Secondly, first strand cDNA synthesis was performed using a random hexamer primer and M-MLV Reverse Transcriptase and second strand cDNA was obtained using DNA polymerase I and RNase H, respectively. Next, adaptors were ligated to blunt ends of the DNA fragments and cDNA fragments (preferentially 150-200 bp lengths) were purified with the AMPure XP system 
(Beckman Coulter, Beverly, USA). In addition, purified cDNA was treated with a total of $3 \mu \mathrm{L}$ USER Enzyme at $37^{\circ} \mathrm{C}$ for $15 \mathrm{~min}$, followed by $95^{\circ} \mathrm{C}$ for $5 \mathrm{~min}$ and PCR was performed in buffer containing Phusion High-Fidelity DNA polymerase, Universal PCR primers, and Index (X) Primer. Lastly, PCR products were purified, and library quality was assessed using the Agilent Bioanalyzer 2100 system. Sequencing was performed on an Illumina ${ }^{\circledR}$ Hiseq 4000 instrument (NEB, Ipswich, MA, USA) to generate $150 \mathrm{bp}$ paired-end reads at Novogene Bioinformatics Institute (Beijing, China).

\subsection{Screening of Differentially Expressed Genes}

High-quality clean reads were aligned to the reference pig genome (S. scrofa 10.2) by TopHat [15]. Subsequently, the mapped reads were assembled by Scripture [16] and Cufflinks [17]. Then, the FPKMs (fragments per kilo-base of exon per million fragments mapped) of coding genes were calculated by Cuffdiff [18]. Finally, genes with a corrected $p$-value $<0.05$ were considered as differentially expressed.

\subsection{GO and KEGG Enrichment Analysis}

Gene ontology (GO) enrichment and kyoto encyclopedia of genes and genomes (KEGG) pathways of differentially expressed genes were performed using DAVID (https://david.ncifcrf.gov/) [19]. $p$-values $<0.05$ were considered significantly enriched GO terms and KEGG pathways.

\subsection{RT-qPCR Confirmation}

Total RNAs of the collected sample tissues were reverse transcribed into cDNA using a PrimeScript ${ }^{\mathrm{TM}}$ RT Reagent kit (Takara, Dalian, China) and the cDNA was stored at $-20{ }^{\circ} \mathrm{C}$ until further analysis. RT-qPCR assays were conducted in a reaction volume of $20 \mu \mathrm{L}$ (containing $9.5 \mu \mathrm{L} 2$ $\times$ SYBR Green Realtime PCR Master Mix, $1 \mu \mathrm{L}$ forward and reverse primers, $1 \mu \mathrm{L}$ cDNA and $7.5 \mu \mathrm{L}$ RNase free $\mathrm{ddH}_{2} \mathrm{O}$ ) with the Roche LightCycler 480II instrument (Roche, Basel, Switzerland) using the SYBR $^{\circledR}$ Green PCR Master Mix (Takara, Dalian, China). The specific primers of genes were designed in NCBI Primer-BLAST online software and the sequence of primers used for RT-qPCR assays are listed in Table 1. The thermal cycler program included an initial denaturation at $95^{\circ} \mathrm{C}$ for $3 \mathrm{~min}$, followed by 40 cycles at $95{ }^{\circ} \mathrm{C}$ for $15 \mathrm{~s}, 58 \pm 1^{\circ} \mathrm{C}$ for $15 \mathrm{~s}$, and $72{ }^{\circ} \mathrm{C}$ for $20 \mathrm{~s}$. Dissociation curves assessed the specificity of PCR products. The relative expression levels of the target genes were calculated with the $2^{-\Delta \Delta C t}$ method [20] and quantified relative to the $\beta$-actin gene.

Table 1. Primers used for real-time quantitative PCR analysis

\begin{tabular}{|c|c|c|c|c|}
\hline Gene & Accession Number & Sequence $\left(5^{\prime}-3^{\prime}\right)$ & Product Size (bp) & Reference \\
\hline \multirow{2}{*}{ Occludin } & \multirow{2}{*}{ NM_001163647.2 } & TCCTGGGTGTGATGGTGTTC & \multirow{2}{*}{144} & \multirow{2}{*}[21]{} \\
\hline & & CGTAGAGTCCAGTCACCGCA & & \\
\hline \multirow{2}{*}{$\mathrm{ZO}-1$} & \multirow{2}{*}{ XM_021098827.1 } & TGAGTTTGATAGTGGCGTTG & \multirow{2}{*}{298} & \multirow{2}{*}[22]{} \\
\hline & & TGGGAGGATGCTGTTGTC & & \\
\hline \multirow{2}{*}{$I L 4 R$} & \multirow{2}{*}{ NM_214340.1 } & GTGGCCCATCTGCCTATCC & \multirow{2}{*}{161} & \\
\hline & & CTGAGCCTGCTCTGTTCTCG & & \\
\hline \multirow{2}{*}{ IL11RA } & \multirow{2}{*}{ XM_021064672.1 } & CCGCAACAGTGTCGCTAGT & \multirow{2}{*}{201} & \\
\hline & & CCACAGAGACCTTCCСCAAA & & \\
\hline \multirow{2}{*}{ CDAN1 } & \multirow{2}{*}{ XM_021097154.1 } & TTTTGAGAAGGGCTTGGGCA & \multirow{2}{*}{160} & \\
\hline & & ATCCGGAGTCTCACCCAAGA & & \\
\hline \multirow{2}{*}{ CCL5 } & \multirow{2}{*}{ NM_001129946.1 } & TGCTTCTTGCTCTTGTCCCA & \multirow{2}{*}{189} & \\
\hline & & GTGCCAAGGGTCCAAAGTTC & & \\
\hline
\end{tabular}


Table 1. Cont.

\begin{tabular}{|c|c|c|c|c|}
\hline Gene & Accession Number & Sequence $\left(5^{\prime}-3^{\prime}\right)$ & Product Size (bp) & Reference \\
\hline \multirow{2}{*}{ IFNE } & \multirow{2}{*}{ NM_001105310.1 } & GTGTCTGCCACACCGGAAAA & \multirow{2}{*}{160} & \\
\hline & & GTGGCTTTCCTCCCAACCAT & & \\
\hline \multirow{2}{*}{ CCL20 } & \multirow{2}{*}{ XM_005672261.3 } & ATCTGGGTGAAACAAGCCGT & \multirow{2}{*}{185} & \\
\hline & & TGGACAAGTCCAAAGAGGCA & & \\
\hline \multirow{2}{*}{$\beta$-actin } & \multirow{2}{*}{ XM_003124280.5 } & AGGCGGACTGTTAGTTGCAT & \multirow{2}{*}{187} & \multirow{2}{*}{ [12] } \\
\hline & & TGTCACCTTCACCGTTCCAG & & \\
\hline
\end{tabular}

\subsection{Statistical Analysis}

All experimental data were analyzed using SPSS software and represented as mean \pm SE. Statistical significance was determined using the two-tailed Student's $t$-test method.

\section{Results}

\subsection{Physiological Changes in C. perfringens Type C Challenged Piglets}

Compared to the three piglets in CG, the three piglets in TG displayed extensive and persistent diarrhea (fecal score $\geq 2$ ) within $1 \mathrm{~d}$ after the challenge with $C$. perfringens type $C$ (Figure $1 \mathrm{~A}$ ). The TG piglets also exhibited high fever $\left(>40^{\circ} \mathrm{C}\right)$ from 2 dpi to 3 dpi (Figure 1B). Throughout the 5 days, all CG piglets showed normal body weight gain; however, the three TG piglets displayed growth retardation (Figure 1C).
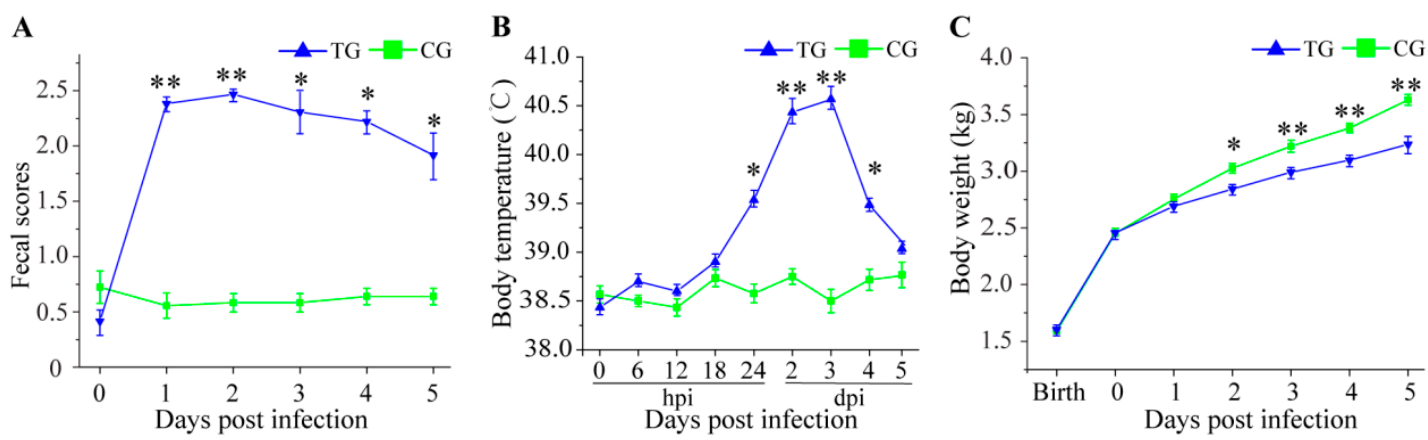

Figure 1. Clinical condition of piglets infected with C. perfringens type C. (A) Fecal scores from C. perfringens type C challenged piglets; (B) Rectal temperature from C. perfringens type $C$ challenged piglets (hpi represents hours post infection); (C) Body weight from C. perfringens type C challenged piglets.

\subsection{Changes to the Small Intestine in C. perfringens Type C Challenged Piglets}

The morphology of the duodena, jejuna, and ilea from CG and TG were examined (Figure 2A-I). Compared with CG, the tissues from TG piglets were abnormal; edema of the lamina propria and submucosa were found in duodenal and jejunal tissues (Figure 2A,B); edema of the lamina propria was also was found in the ileal tissue (Figure 2C). Furthermore, there was inflammatory cell infiltration in the duodenal and ileal tissues (Figure 2D,F) and infiltration of small amounts of neutrophile granulocytes appeared in the jejuna (Figure 2E). Additionally, in the jejunal and ileal tissues, villi length was significantly lower in TG than that in CG (Figure 2G). Between CG and TG, significant differences were observed for crypt depth, which was higher in the duodenal, jejunal and ileal tissue after infection (Figure 2H). The ratio of villus width to crypt depth in the three intestinal tissues of TG was lower than that in CG (Figure 2I). To assess the integrity of the intestinal membrane, we detected the expression level of ZO-1 and Occludin genes using RT-qPCR. Compared to piglets in CG, two genes were significantly decreased in TG, especially in the ileum (Figure 3A,B). 

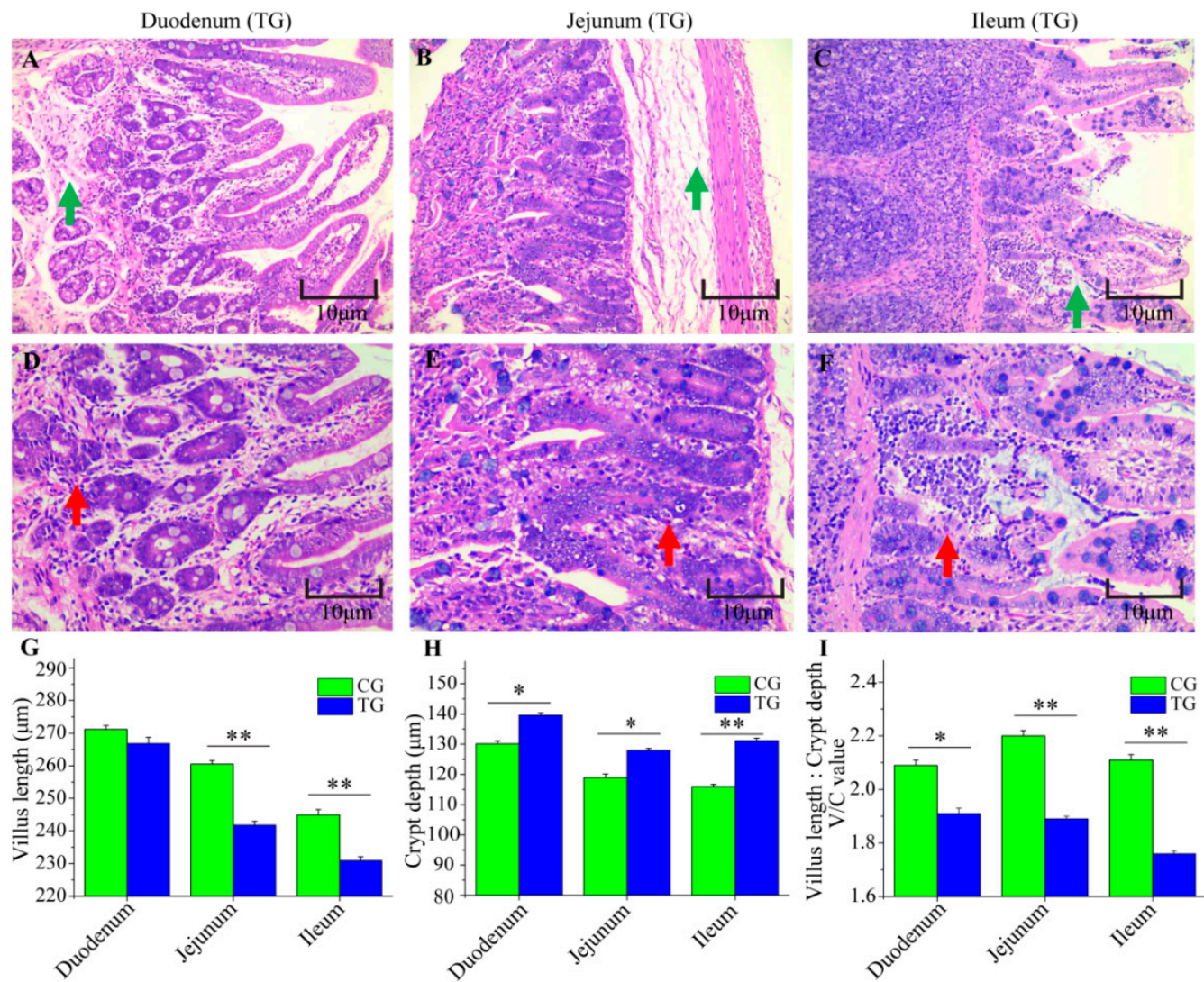

Figure 2. Changes in the small intestine. (A) Edema of the lamina propria and submucosa (green arrow); (B) Edema of the lamina propria and submucosa (green arrow); (C) Edema of the lamina propria (green arrow); (D) Inflammatory cell infiltration (red arrow); (E) Infiltration with neutrophil granulocytes (red arrow); (F) Inflammatory cell infiltration (red arrow); (G)Villus height; (H) Crypt depth; (I) The ratio of villus width/crypt depth. Asterisk above bars indicates a significant difference $\left({ }^{*} p<0.05\right.$, ** $p<0.01)$. Data are shown as mean $\pm \mathrm{SE}$ of thirty replicates.
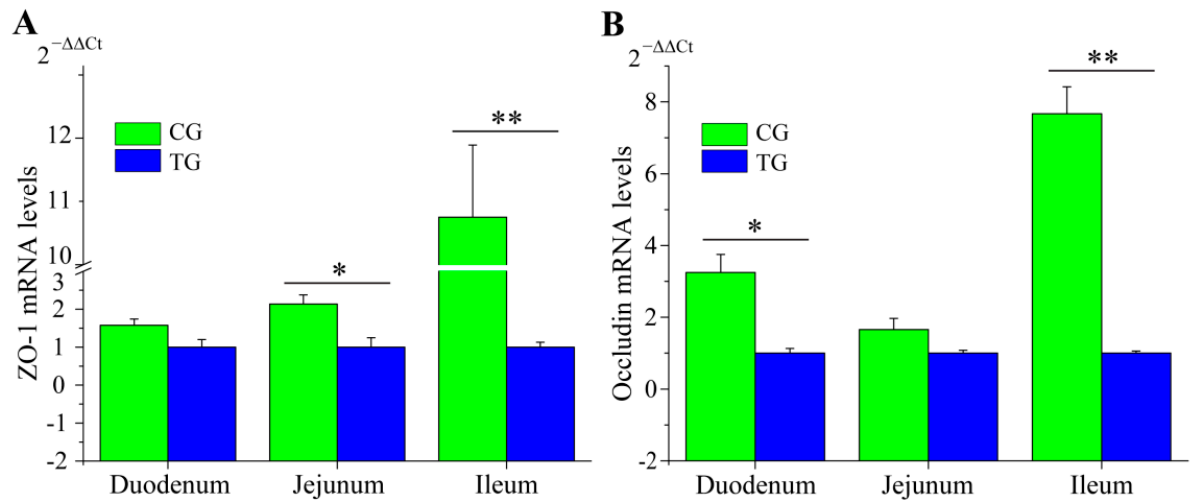

Figure 3. Tight junction protein genes ZO-1 (A) and Occludin (B) mRNA levels in the small intestinal by RT-qPCR. Data are presented as mean \pm SE of three replicates $\left({ }^{*} p<0.05 ;{ }^{* *} p<0.01\right)$.

\subsection{Dynamic Change of Inflammatory Cytokines and $\operatorname{sig} A$}

In the gut lumen, $\operatorname{sg} A$ is treated as the first line of defense in protecting the intestinal epithelium from pathogens. Fecal sIgA in TG and CG was examined throughout the experiment. The results indicated that the sIgA levels in TG were not different at 0 dpi and gradually increased at $1 \mathrm{dpi}$. Obviously, piglets in TG had significantly higher fecal sIgA levels at $3 \mathrm{dpi}$ and $5 \mathrm{dpi}$ as compared to 
CG (Figure 4C). After exposure to $C$. perfringens type $C$, the content of pro-inflammation cytokines IL-6 and TNF- $\alpha$ was increased from 1 dpi to 5 dpi (Figure 4 A,B).
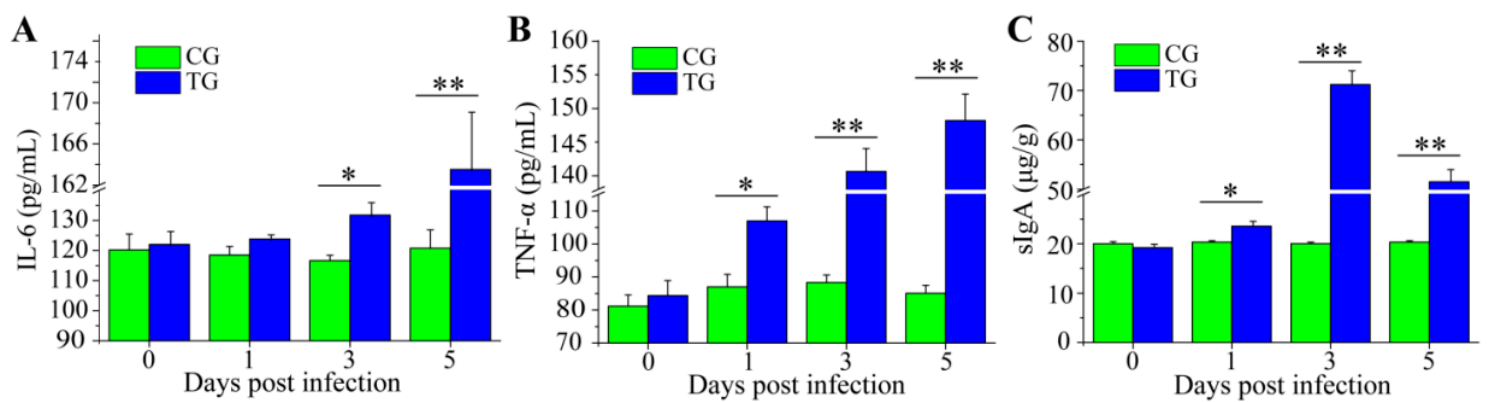

Figure 4. Immune response to C. perfringens type $C$ infection. Serum concentration of pro-inflammatory cytokines IL-6 (A), TNF- $\alpha$ (B), and the fecal levels of $\operatorname{sigA}(\mathbf{C})$ at $0,1,3$, and 5 dpi were evaluated by ELISA. Each sample was assayed in three replicates. Values are presented as mean $\pm \mathrm{SE}\left({ }^{*} p<0.05\right.$; ** $p<0.01)$.

\subsection{DEGs of Ileum after Infection}

We explored the variation in DEGs using pairwise comparisons between CG and TG. No differences were observed in gene expression between CG and TG (Figure 5A). A total of 2181 DEGs (including 1021 up-regulated and 1160 down-regulated genes) were found. In addition, the heatmap displayed all DEGs between the two groups and indicated that three samples in CG or TG had similar expression patterns (Figure 5B).

A

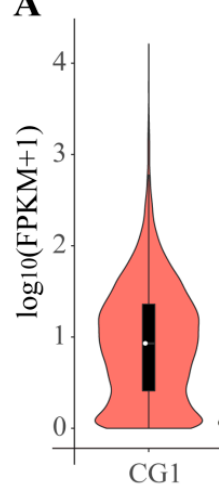

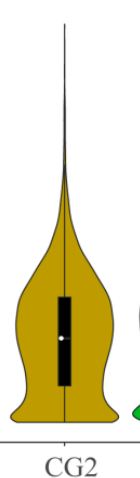

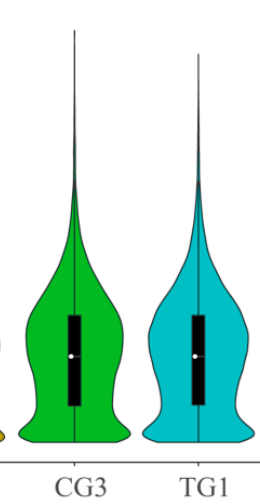

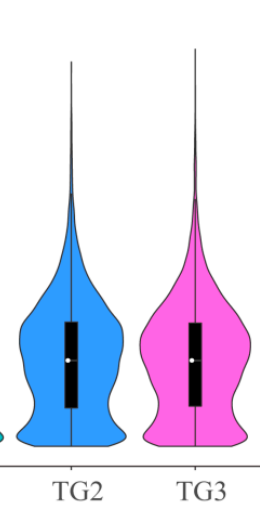

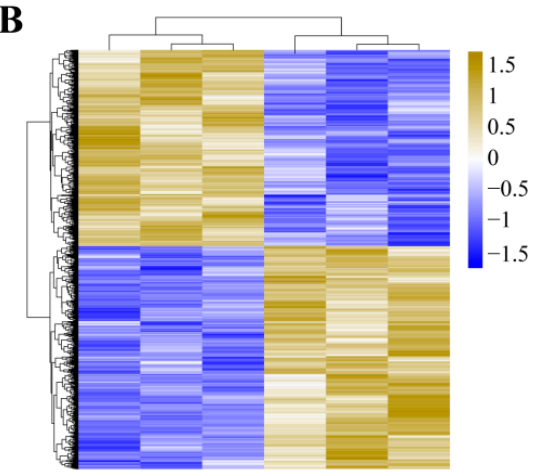

TG3 TG1 TG2 CG3 CG1 CG2

Figure 5. (A) Expression level indicated by $\log 10($ FPKM +1$)$ in the mRNAs between control piglets (CG) and treatment group (TG); (B) Clustered heatmap of the differentially expressed mRNAs in paired samples of CG and TG. Rows represent mRNAs while columns represent different treated samples.

\subsection{Functional Analysis of DEGs}

To explore DEGs function, GO analysis was performed on three different aspects, including biological process (BP), molecular function (MF), and cellular components (CC). In order to identify the potential and useful genes for deep investigation, the top 30 GO terms were screened $(p$-value $<0.05)$ and are listed in Figure 6. GO analysis showed that the DEGs between the two groups were enriched in the protein autoubiquitination and cellular calcium ion homeostasis in BP; in the microtubule cytoskeleton, extrinsic component of the membrane, and endoplasmic reticulum membrane of the CC; and in the nucleic acid binding and transcription regulatory region DNA binding in MF (Figure 6).

To further define DEGs function in the ileum after C. perfringens type $C$ infection, the DAVID database was used to analyze these DEGs. The top 30 enriched KEGG pathways of the DEGs are listed according to a $p$-value $<0.05$ in Figure 7 . Several functional classifications were selected to 
potentially play important roles related to $C$. perfringens type $C$ infection, including $B$ cell receptor signaling pathway, T cell receptor signaling pathway, NF-kappa B signaling pathway, TNF signaling pathway, and Toll-like receptor signaling pathway.

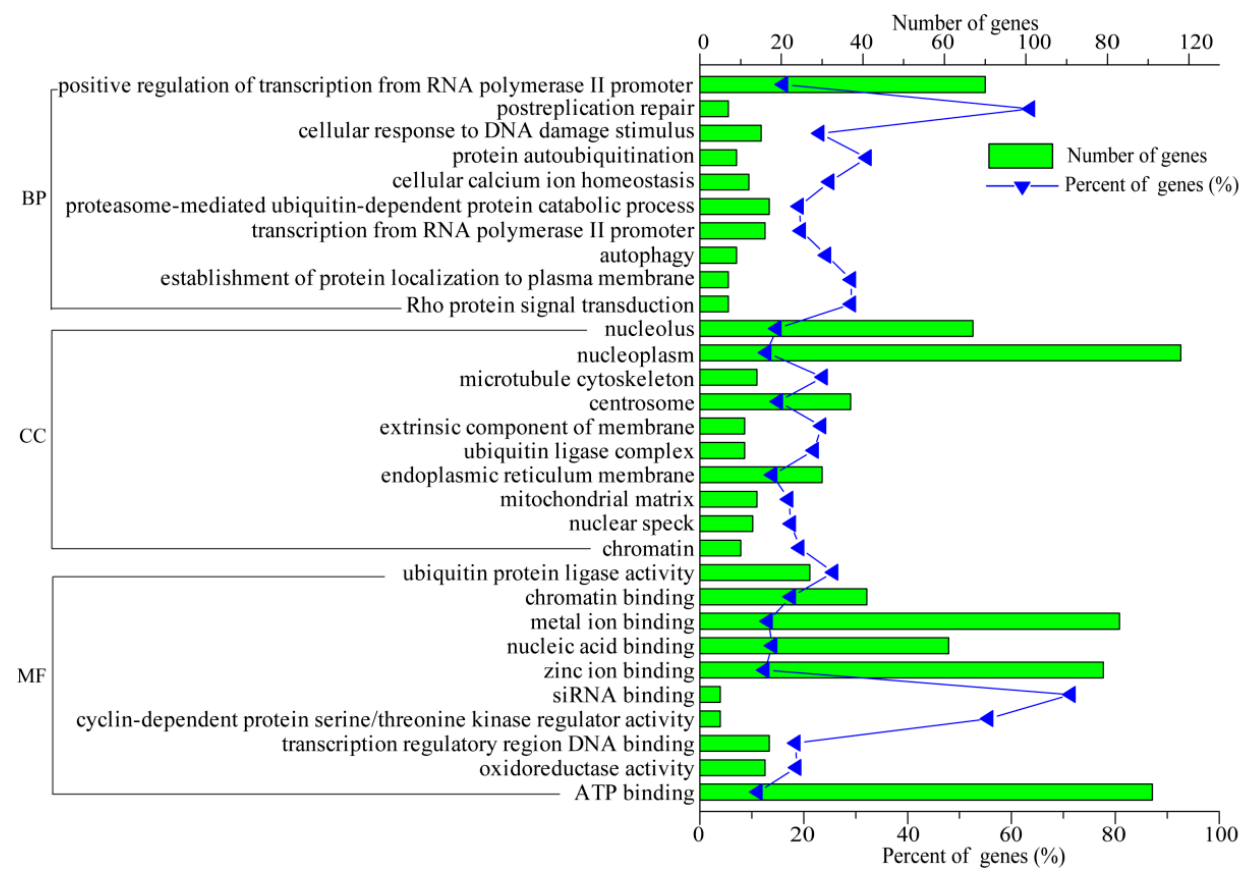

Figure 6. Gene ontology (GO) terms were classified into cellular component (CC), molecular function (MF), and biological process (BP). The top $30 \mathrm{GO}$ terms are selected according to a $p$-value $<0.05$.

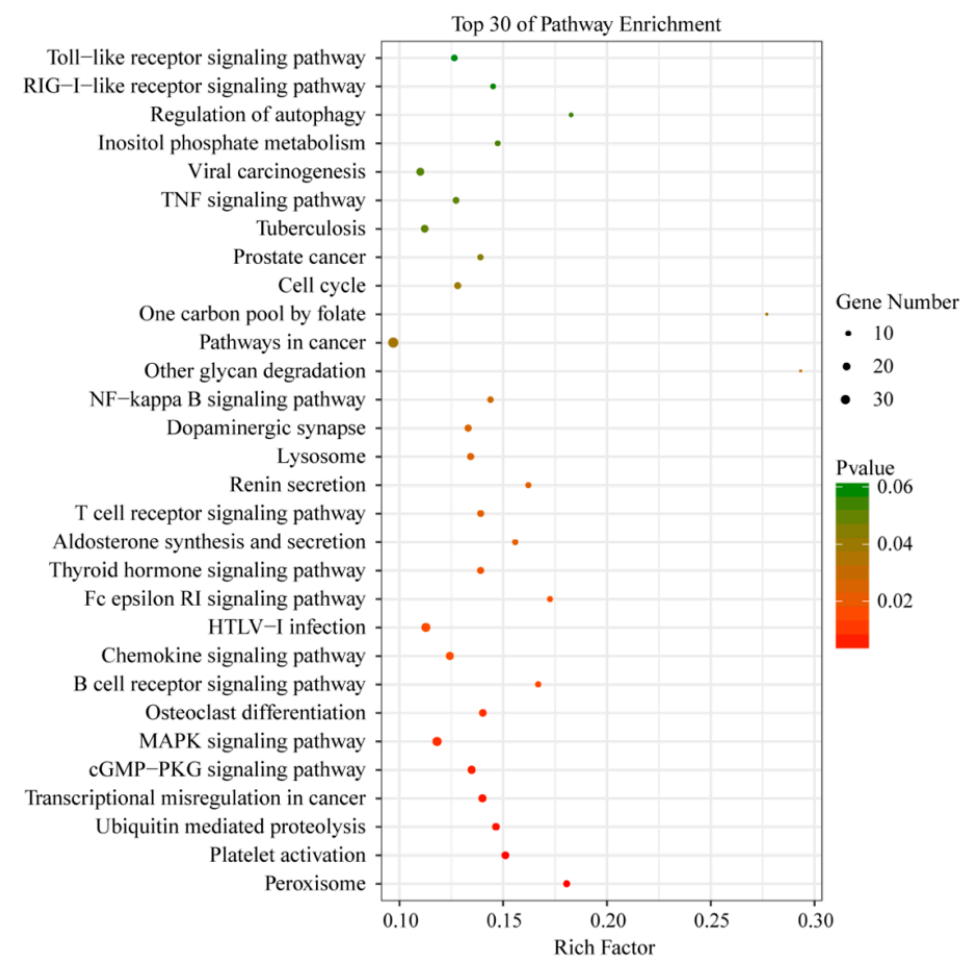

Figure 7. KEGG pathways of the differentially expressed genes. Rich factor is the ratio of the number of genes located in the KEGG pathway to the total number of genes in the KEGG pathway. The top 30 KEGG pathways are listed according to a $p$-value $<0.05$. 


\subsection{RT-qPCR Validation of RNA-Seq Data}

To evaluate the DEGs identified by the transcriptome sequencing data, we detected the expression levels of six immune-related genes, which were mainly enriched in host immune defense responses against $C$. perfringens type $C$ infection. These genes included IL4R (Interleukin 4 receptor), IL11RA (Interleukin 11 receptor subunit alpha), CDAN1 (Codanin 1), CCL5 (C-C motif chemokine ligand 5), IFNE (Interferon epsilon), and CCL20 (C-C motif chemokine ligand 20). The RT-qPCR results were consistent with the results of RNA-Seq analysis, which demonstrated that the RNA-Seq data was highly reliable and accurate in this study (Figure 8).
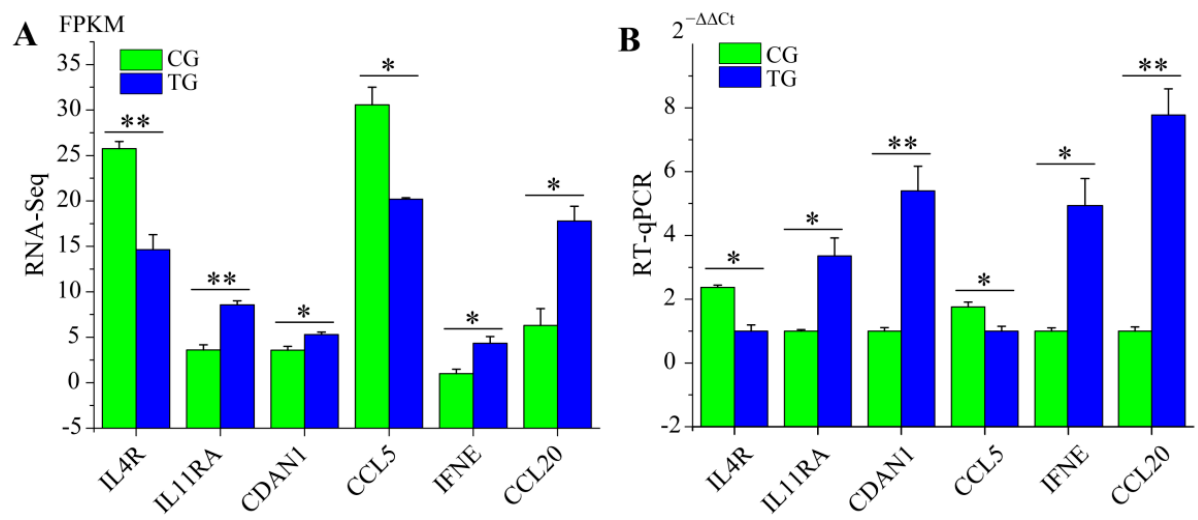

Figure 8. Verification of RT-qPCR for some differentially expressed genes. (A) RNA-Seq results.

(B) RT-qPCR results. The results are shown as the mean \pm SE of three replicates. $\left({ }^{*} p<0.05 ;{ }^{* *} p<0.01\right)$.

\section{Discussion}

C. perfringens type $\mathrm{C}$ causes diarrhea characterized by high morbidity and mortality in pigs, especially newborn and suckling piglets [4]. The occurrence of diarrhea is mainly induced by contact with infected pigs or contaminated food. In recent years, $C$. perfringens type $C$ has become one of the most widespread bacterial infections in the global pig industry and has resulted in great economic loss [4]. To date, RNA-Seq technology has been used to disclose the biological processes and the development of some diseases, including necrotic enteritis $[11,23,24]$, diarrhea $[25,26]$, arthritis $[27,28]$, and even various cancers [29,30]. Additionally, some studies have explored transcriptome sequences of different tissues (including spleen and small intestine) in Escherichia coli [31,32] and Streptococcus suis type 2 [33] infected pigs, giving a huge amount of basic data for illustrating the mechanism of pathogenic bacteria in pigs. A greater understanding of piglet response to $C$. perfringens type $C$ infection may help us prevent and control diarrhea caused by this bacterium. However, knowledge of the mechanics of piglet response to C. perfringens type $C$ is still limited. Therefore, in this study, we analyzed changes in the small intestine and investigated the transcriptome of the ileum in normal piglets and in piglets at $5 \mathrm{dpi}$ with $C$. perfringens type $C$ to accelerate investigations into the molecular events of infection. In short, results from our current study indicated that transcriptome analysis of RNA-Seq data may assist in the understanding of the precise mechanisms of diarrhea caused by C. perfringens type $C$ in piglets.

It is known that pigs challenged by various pathogenic bacteria display diarrhea, growth retardation, and high fever [22,34,35]. In our study, we also found that piglets in TG exhibited diarrhea and body weight loss (Figure 1A,C), which suggested that $C$. perfringens type $C$ and its fatal toxins could impair the integrity of the intestinal barrier and then caused diarrhea; persistent diarrhea then led to body weight loss. C. perfringens type $C$ and its toxins may trigger the innate immune response, causing an obvious high fever in piglets (Figure 1B). Previous reports show that the main target organ for $C$. perfringens type $C$ is the small intestine in animals $[4,36]$. H\&E staining was used to determine whether there were pathological changes in the small intestine of infected piglets in the 
current study and revealed the principle lesions of inflammation and edema (Figure 2A-F). This result was consistent with our previous results in the small intestine of piglets challenged by C. perfringens type C [12]. Villi of the small intestine play an important role in absorbing nutrients for animal growth and development $[37,38]$. Moreover, previous studies report that the infection may reduce the mitotic potential of the villi, causing a decrease in villi height and an increase in villi depth $[22,39,40]$. Indeed, piglets in TG had lower villi and larger crypts in the small intestine as compared with CG (Figure 2G-I), which suggested that $C$. perfringens type $C$ induced enteric changes.

Tight junction proteins (including ZO-1 and Occludin) seal the paracellular space between epithelial cells for maintaining the integrity of the intestinal barrier [41]. The integrated tight junction barrier plays key roles in ion transport, inflammation during intestinal epithelial responses to enteric pathogenic bacteria, such as enterotoxigenic E. coli, and Salmonella [42-44]. Moreover, damage to the integrity of the intestinal barrier increases the risk of infection in animals [45,46]. In this study, we observed that the expression level of $\mathrm{ZO}-1$ and Occludin were decreased after $\mathrm{C}$. perfringens type $\mathrm{C}$ infection (Figure 3A,B). These results suggested that $C$. perfringens type $C$ can break the integrity of the intestinal barrier by destabilizing and dissociating the tight junction proteins ( $\mathrm{ZO}-1$ and Occludin) in the small intestine. We speculated that these changes of the small intestine could lead to diarrhea, which would, in turn, lead to growth retardation.

Proinflammatory cytokines (such as IL-6 and TNF- $\alpha$ ) play an important role in the regulation of enteric pathogenic bacteria and the concentration of these cytokines in the serum of animals is usually increased after enteric pathogenic bacterial infection $[22,47,48]$. IL-6 plays a key role in stimulating B cell proliferation and T cell proliferation, and antibody production $[49,50]$. TNF- $\alpha$ is associated with cell-mediated immune response and confers immunity against harmful agents including bacteria, viruses, and even tumor cells [51,52]. In our study, compared to the piglets in CG, the levels of IL-6 and TNF- $\alpha$ in serum were increased in TG piglets (Figure 4A,B). The increased concentration of IL-6 and TNF- $\alpha$ were beneficial for enhancing immunity and thus resisting $C$. perfringens type C. sIgA serves as an important indicator of mucosal immunology, it plays a vital role in protecting the epithelium from pathogens, and fecal sIgA levels are related to microorganism infection [53,54]. In our study, we observed that the concentration of fecal sIgA in CG was lower than that in TG (Figure 4C). These results indicated that the host immune system response was activated after piglets were infected with C. perfringens type C.

We also screened and verified differentially expressed transcripts in C. perfringens type C-infected piglet's ileal tissues using RNA-Seq. GO terms and KEGG signaling pathway analyses were performed to confirm differentially expressed gene function. By comparing the transcriptome data of the ileum from TG and CG, the results showed that most of the DEGs were involved in many immunological responses of the KEGG pathways, including the NF-kappa B signaling pathway, TNF signaling pathway, and Toll-like receptor signaling pathway (Figure 7). These KEGG pathways are also enriched in the small intestine tissue of chickens infected with C. perfringens type A [10,11]. In our previous study, we also found that these KEGG pathways were enriched in piglets challenged with C. perfringens type $C$ infection [12]. The latter results suggest that these KEGG pathways play crucial roles in anti-C. perfringens type $C$ response and piglet defense during $C$. perfringens type $C$ infection. Additionally, we detected the expression levels of six differentially expressed genes in piglet spleens between CG and TG. IFNE belongs to a type I IFN and plays key roles in resisting pathogenic microorganisms $[55,56]$. After $C$. perfringens type C infection, the expression of IFNE was significantly up-regulated. Studies have found that CCL20 is a chemokine with antimicrobial activity [57,58]. We observed that the expression level of CCL20 was higher in TG than that in CG. This indicated that up-regulated CCL20 may inhibit C. perfringens type C invasion and reproduction in piglets. In summary, these immune genes (such as IFNE and CCL20) may play an important role via KEGG pathways in the response of piglets to $C$. perfringens type $C$ infection. 


\section{Conclusions}

In this study, we compared the fecal scores, rectal temperature, body weight, pathological change of the small intestine, and pro-inflammation cytokines (IL-6 and TNF- $\alpha$ ) between control piglets (CG) and piglets challenged with $C$. perfringens type C (TG). Subsequently, we used RNA-Seq to investigate the genetic profile of the ileum in piglets. The study revealed a set of candidate genes (such as IFNE and CCL20) that may contribute to $C$. perfringens type $C$ infection in piglets. This study offers information towards a deeper understanding of the immune response of piglets to $C$. perfringens type $C$ infection.

Author Contributions: Z.Y. performed the main experiment and wrote the paper; T.J. and Q.Y. conceived and designed the experiments; X.H. and W.S. participated in analyzing the data; L.C., S.L. and P.W. were involved in the study; S.G. guided the execution of the study and revised the manuscript.

Funding: This research was funded by the Discipline Construction Fund Project of Gansu Agricultural University (GSAU-XKJS-2018-041).

Acknowledgments: We thank Charlesworth Publishing Services Ltd for providing us with language editing.

Conflicts of Interest: The authors declare no conflicts of interest.

\section{References}

1. Li, J.H.; Adams, V.; Bannam, T.L.; Miyamoto, K.; Garcia, J.P.; Uzal, F.A.; Rood, J.I.; McClane, B.A. Toxin plasmids of Clostridium perfringens. Microbiol. Mol. Biol. Rev. 2013, 77, 208-233. [CrossRef] [PubMed]

2. Songer, J.G.; Uzal, F.A. Clostridial enteric infections in pigs. J. Vet. Diagn. Investig. 2005, 17, 528-536. [CrossRef] [PubMed]

3. Songer, J.G. Clostridial diseases of small ruminants. Vet. Res. 1998, 29, 219-232.

4. Uzal, F.A.; McClane, B.A. Recent progress in understanding the pathogenesis of Clostridium perfringens type C infections. Vet. Microbiol. 2011, 153, 37-43. [CrossRef] [PubMed]

5. Petit, L.; Gibert, M.; Popoff, M.R. Clostridium perfringens: Toxinotype and genotype. Trends Microbiol. 1999, 7, 104-110. [CrossRef]

6. Songer, J.G. Clostridial enteric diseases of domestic animals. Clin. Microbiol. Rev. 1996, 9, 216-234. [CrossRef]

7. Miclard, J.; Jaggi, M.; Sutter, E.; Wyder, M.; Grabscheid, B.; Posthaus, H. Clostridium perfringens beta-toxin targets endothelial cells in necrotizing enteritis in piglets. Vet. Microbiol. 2009, 137, 320-325. [CrossRef]

8. Vidal, J.E.; McClane, B.A.; Saputo, J.; Parker, J.; Uzal, F.A. Effects of Clostridium perfringens beta-toxin on the rabbit small intestine and colon. Infect. Immun. 2008, 76, 4396-4404. [CrossRef]

9. Fisher, D.J.; Fernandez-Miyakawa, M.E.; Sayeed, S.; Poon, R.; Adams, V.; Rood, J.I.; Uzal, F.A.; McClane, B.A. Dissecting the contributions of Clostridium perfringens type $C$ toxins to lethality in the mouse intravenous injection model. Infect. Immun. 2006, 74, 5200-5210. [CrossRef]

10. Anh Duc, T.; Hong, Y.; Ban, J.; Park, B.; Hoang, T.C.; Hong, Y.H.; Lillehoj, H.S. Analysis of differentially expressed genes in necrotic enteritis-infected fayoumi chickens using RNA sequencing. J. Poult. Sci. 2017, 54, 121-133.

11. Truong, A.D.; Hong, Y.H.; Lillehoj, H.S. High-throughput sequencing reveals differing immune responses in the intestinal mucosa of two inbred lines afflicted with necrotic enteritis. Vet. Immunol. Immunopathol. 2015, 166, 116-124. [CrossRef]

12. Yan, Z.; Jiang, T.; Wang, P.; Huang, X.; Yang, Q.; Sun, W.; Gun, S. Circular rna expression profile of spleen in a Clostridium perfringens type C-induced piglet model of necrotizing enteritis. FEBS Open Bio 2018, 8, 1722-1732. [CrossRef]

13. Kelly, D.; O'Brien, J.J.; McCracken, K.J. Effect of creep feeding on the incidence, duration and severity of post-weaning diarrhoea in pigs. Res. Vet. Sci. 1990, 49, 223-228. [CrossRef]

14. Yang, Q.L.; Kong, J.J.; Wang, D.W.; Zhao, S.G.; Gun, S.B. Swine leukocyte antigen-DQA gene variation and its association with piglet diarrhea in Large White, Landrace and Duroc. Asian-Australas. J. Anim. Sci. 2013, 26, 1065-1071. [CrossRef] [PubMed]

15. Trapnell, C.; Pachter, L.; Salzberg, S.L. Tophat: Discovering splice junctions with RNA-seq. Bioinformatics 2009, 25, 1105-1111. [CrossRef] 
16. Guttman, M.; Garber, M.; Levin, J.Z.; Donaghey, J.; Robinson, J.; Adiconis, X.; Fan, L.; Koziol, M.J.; Gnirke, A.; Nusbaum, C.; et al. Ab initio reconstruction of cell type-specific transcriptomes in mouse reveals the conserved multi-exonic structure of lincRNAs. Nat. Biotechnol. 2010, 28, 503-510. [CrossRef] [PubMed]

17. Trapnell, C.; Roberts, A.; Goff, L.; Pertea, G.; Kim, D.; Kelley, D.R.; Pimentel, H.; Salzberg, S.L.; Rinn, J.L.; Pachter, L. Differential gene and transcript expression analysis of RNA-seq experiments with Tophat and Cufflinks. Nat. Protoc. 2012, 7, 562-578. [CrossRef] [PubMed]

18. Trapnell, C.; Williams, B.A.; Pertea, G.; Mortazavi, A.; Kwan, G.; van Baren, M.J.; Salzberg, S.L.; Wold, B.J.; Pachter, L. Transcript assembly and quantification by RNA-seq reveals unannotated transcripts and isoform switching during cell differentiation. Nat. Biotechnol. 2010, 28, 511-515. [CrossRef] [PubMed]

19. Huang, D.W.; Sherman, B.T.; Lempicki, R.A. Bioinformatics enrichment tools: Paths toward the comprehensive functional analysis of large gene lists. Nucleic Acids Res. 2009, 37, 1-13. [CrossRef]

20. Livak, K.J.; Schmittgen, T.D. Analysis of relative gene expression data using real-time quantitative PCR and the 2(-delta delta c(t)) method. Methods 2001, 25, 402-408. [CrossRef] [PubMed]

21. Tossou, M.C.B.; Liu, H.; Bai, M.; Chen, S.; Cai, Y.; Duraipandiyan, V.; Liu, H.; Adebowale, T.O.; Al-Dhabi, N.A.; Long, L.; et al. Effect of high dietary tryptophan on intestinal morphology and tight junction protein of weaned pig. BioMed Res. Int. 2016, 2016, 2912418. [CrossRef] [PubMed]

22. Huang, G.; Li, X.; Lu, D.; Liu, S.; Suo, X.; Li, Q.; Li, N. Lysozyme improves gut performance and protects against enterotoxigenic Escherichia coli infection in neonatal piglets. Vet. Res. 2018, 49. [CrossRef] [PubMed]

23. Higgins, S.E.; Wolfenden, A.D.; Tellez, G.; Hargis, B.M.; Porter, T.E. Transcriptional profiling of cecal gene expression in probiotic- and Salmonella-challenged neonatal chicks. Poult. Sci. 2011, 90, 901-913. [CrossRef] [PubMed]

24. Kim, D.K.; Lillehoj, H.S.; Jang, S.I.; Lee, S.H.; Hong, Y.H.; Cheng, H.H. Transcriptional profiles of host-pathogen responses to necrotic enteritis and differential regulation of immune genes in two inbreed chicken lines showing disparate disease susceptibility. PLOS ONE 2014, 9, e114960. [CrossRef] [PubMed]

25. Park, H.-E.; Park, H.-T.; Jung, Y.H.; Yoo, H.S. Gene expression profiles of immune-regulatory genes in whole blood of cattle with a subclinical infection of Mycobacterium avium subsp paratuberculosis. PLoS ONE 2018, 13, e0196502. [CrossRef]

26. Park, S.K.; Jeong, J.Y.; Cho, E.S.; Jeong, Y.D.; Park, C.S. RNA-seq reveals differentially expressed genes of pig vaccinated with modified live attenuated porcine epidemic diarrhea. Pak. J. Zool. 2017, 49, 1107-1110. [CrossRef]

27. Stephenson, W.; Donlin, L.T.; Butler, A.; Rozo, C.; Bracken, B.; Rashidfarrokhi, A.; Goodman, S.M.; Ivashkiv, L.B.; Bykerk, V.P.; Orange, D.E.; et al. Single-cell RNA-seq of rheumatoid arthritis synovial tissue using low-cost microfluidic instrumentation. Nat. Commun. 2018, 9, 791. [CrossRef]

28. Yu, F.; Duan, C.; Zhang, X.; Yao, D.; Si, G.; Gao, Y.; Gao, Z.; Umer, F.; Guo, X. RNA-seq analysis reveals different gene ontologies and pathways in rheumatoid arthritis and kashin-beck disease. Int. J. Rheum. Dis. 2018, 21, 1686-1694. [CrossRef]

29. Damiani, C.; Maspero, D.; Di Filippo, M.; Colombo, R.; Pescini, D.; Graudenzi, A.; Westerhoff, H.V.; Alberghina, L.; Vanoni, M.; Mauri, G. Integration of single-cell RNA-seq data into population models to characterize cancer metabolism. PLoS Comput. Biol. 2019, 15, e1006733. [CrossRef]

30. Zhao, Y.H.; Qin, X.L.; Yang, J.Y.; Liao, Y.W.; Wu, X.Z.; Zheng, H.P. Identification and expression analysis of ceftriaxone resistance-related genes in neisseria gonorrhoeae integrating RNA-seq data and qRT-PCR validation. J. Glob. Antimicrob. Resist. 2019, 16, 202-209. [CrossRef]

31. Sargeant, H.R.; McDowall, K.J.; Miller, H.M.; Shaw, M.-A. Dietary zinc oxide affects the expression of genes associated with inflammation: Transcriptome analysis in piglets challenged with ETEC k88. Vet. Immunol. Immunopathol. 2010, 137, 120-129. [CrossRef]

32. Trevisi, P.; Latorre, R.; Priori, D.; Luise, D.; Archetti, I.; Mazzoni, M.; D'Inca, R.; Bosi, P. Effect of feed supplementation with live yeast on the intestinal transcriptome profile of weaning pigs orally challenged with Escherichia coli F4. Animal 2017, 11, 33-44. [CrossRef]

33. Gaur, U.; Xiong, Y.Y.; Luo, Q.P.; Yuan, F.Y.; Wu, H.Y.; Qiao, M.; Wimmers, K.; Li, K.; Mei, S.Q.; Liu, G.S. Breed-specific transcriptome response of spleen from six to eight week old piglet after infection with Streptococcus suis type 2. Mol. Biol. Rep. 2014, 41, 7865-7873. [CrossRef] 
34. Splichalova, A.; Jenistova, V.; Splichalova, Z.; Splichal, I. Colonization of preterm gnotobiotic piglets with probiotic lactobacillus rhamnosus gg and its interference with Salmonella typhimurium. Clin. Exp. Immunol. 2019, 195, 381-394. [CrossRef] [PubMed]

35. Zhang, H.; Xu, Y.; Zhang, Z.; You, J.; Yang, Y.; Li, X. Protective immunity of a multivalent vaccine candidate against piglet diarrhea caused by enterotoxigenic Escherichia coli (ETEC) in a pig model. Vaccine 2018, 36, 723-728. [CrossRef]

36. Sayeed, S.; Uzal, F.A.; Fisher, D.J.; Saputo, J.; Vidal, J.E.; Chen, Y.; Gupta, P.; Rood, J.I.; McClane, B.A. Beta toxin is essential for the intestinal virulence of Clostridium perfringens type $\mathrm{C}$ disease isolate CN3685 in a rabbit ileal loop model. Mol. Microbiol. 2008, 67, 15-30. [CrossRef] [PubMed]

37. Lentle, R.G.; de Loubens, C. A review of mixing and propulsion of chyme in the small intestine: Fresh insights from new methods. J. Comp. Physiol. B 2015, 185, 369-387. [CrossRef]

38. Al Masri, S.; Hunigen, H.; Al Aiyan, A.; Rieger, J.; Zentek, J.; Richardson, K.; Plendl, J. Influence of age at weaning and feeding regimes on the postnatal morphology of the porcine small intestine. J. Swine Health Prod. 2015, 23, 186-203.

39. Adhikari, P.; Cosby, D.E.; Cox, N.A.; Franca, M.S.; Williams, S.M.; Gogal, R.M.; Ritz, C.W.; Kim, W.K. Effect of dietary fructooligosaccharide supplementation on internal organs salmonella colonization, immune response, ileal morphology, and ileal immunohistochemistry in laying hens challenged with salmonella enteritidis. Poult. Sci. 2018, 97, 2525-2533. [CrossRef] [PubMed]

40. Zhou, C.L.; Liu, Z.Z.; Jiang, J.C.; Yu, Y.; Zhang, Q. Differential gene expression profiling of porcine epithelial cells infected with three enterotoxigenic Escherichia coli strains. BMC Genom. 2012, 13, 330. [CrossRef] [PubMed]

41. Li, X.; Akhtar, S.; Choudhry, M.A. Alteration in intestine tight junction protein phosphorylation and apoptosis is associated with increase in IL-18 levels following alcohol intoxication and burn injury. Biochim. Biophys. Acta-Mol. Basis Dis. 2012, 1822, 196-203. [CrossRef] [PubMed]

42. Martens, E.C.; Neumann, M.; Desai, M.S. Interactions of commensal and pathogenic microorganisms with the intestinal mucosal barrier. Nat. Rev. Microbiol. 2018, 16, 457-470. [CrossRef]

43. Lepine, A.F.P.; de Wit, N.; Oosterink, E.; Wichers, H.; Mes, J.; de Vos, P. Lactobacillus acidophilus attenuates Salmonella-induced stress of epithelial cells by modulating tight-junction genes and cytokine responses. Front. Microbiol. 2018, 9. [CrossRef] [PubMed]

44. Wang, J.; Ji, H.; Wang, S.; Liu, H.; Zhang, W.; Zhang, D.; Wang, Y. Probiotic lactobacillus plantarum promotes intestinal barrier function by strengthening the epithelium and modulating gut microbiota. Front. Microbiol. 2018, 9. [CrossRef]

45. Hendrikx, T.; Schnabl, B. Antimicrobial proteins: Intestinal guards to protect against liver disease. J. Gastroenterol. 2019, 54, 209-217. [CrossRef] [PubMed]

46. Bhat, A.A.; Uppada, S.; Achkar, I.W.; Hashem, S.; Yadav, S.K.; Shanmugakonar, M.; Al-Naemi, H.A.; Haris, M.; Uddin, S. Tight junction proteins and signaling pathways in cancer and inflammation: A functional crosstalk. Front. Physiol. 2019, 9. [CrossRef]

47. He, F.; Wu, C.; Li, P.; Li, N.; Zhang, D.; Zhu, Q.; Ren, W.; Peng, Y. Functions and signaling pathways of amino acids in intestinal inflammation. BioMed Res. Int. 2018, 2018, 9171905. [CrossRef] [PubMed]

48. Peterson, L.W.; Artis, D. Intestinal epithelial cells: Regulators of barrier function and immune homeostasis. Nat. Rev. Immunol. 2014, 14, 141-153. [CrossRef]

49. Hunter, C.A.; Jones, S.A. IL-6 as a keystone cytokine in health and disease. Nat. Immunol. 2015, 16, 448-457. [CrossRef]

50. Mihara, M.; Hashizume, M.; Yoshida, H.; Suzuki, M.; Shiina, M. IL-6/IL-6 receptor system and its role in physiological and pathological conditions. Clin. Sci. 2012, 122, 143-159. [CrossRef]

51. Grijalva, C.G.; Chen, L.; Delzell, E.; Baddley, J.W.; Beukelman, T.; Winthrop, K.L.; Griffin, M.R.; Herrinton, L.J.; Liu, L.; Ouellet-Hellstrom, R.; et al. Initiation of tumor necrosis factor-alpha antagonists and the risk of hospitalization for infection in patients with autoimmune diseases. Jama 2011, 306, 2331-2339. [CrossRef] [PubMed]

52. Horiuchi, T.; Mitoma, H.; Harashima, S.-I.; Tsukamoto, H.; Shimoda, T. Transmembrane TNF-alpha: Structure, function and interaction with anti-TNF agents. Rheumatology 2010, 49, 1215-1228. [CrossRef] [PubMed]

53. Pabst, O. New concepts in the generation and functions of IgA. Nat. Rev. Immunol. 2012, 12, 821-832. [CrossRef] 
54. Mantis, N.J.; Rol, N.; Corthesy, B. Secretory IgA's complex roles in immunity and mucosal homeostasis in the gut. Mucosal Immunol. 2011, 4, 603-611. [CrossRef] [PubMed]

55. Garcia-Minambres, A.; Eid, S.G.; Mangan, N.E.; Pade, C.; Lim, S.S.; Matthews, A.Y.; de Weerd, N.A.; Hertzog, P.J.; Mak, J. Interferon epsilon promotes hiv restriction at multiple steps of viral replication. Immunol. Cell Biol. 2017, 95, 478-483. [CrossRef] [PubMed]

56. Sang, Y.; Bergkamp, J.; Blecha, F. Molecular evolution of the porcine type I interferon family: Subtype-specific expression and antiviral activity. PLoS ONE 2014, 9, e112378. [CrossRef]

57. Hielpos, M.S.; Ferrero, M.C.; Fernandez, A.G.; Bonetto, J.; Giambartolomei, G.H.; Fossati, C.A.; Baldi, P.C. CCL20 and beta-defensin 2 production by human lung epithelial cells and macrophages in response to brucella abortus infection. PLoS ONE 2015, 10, e0140408. [CrossRef] [PubMed]

58. Guesdon, W.; Auray, G.; Pezier, T.; Bussiere, F.I.; Drouet, F.; Le Vern, Y.; Marquis, M.; Potiron, L.; Rabot, S.; Bruneau, A.; et al. CCL20 displays antimicrobial activity against cryptosporidium parvum, but its expression is reduced during infection in the intestine of neonatal mice. J. Infect. Dis. 2015, 212, 1332-1340. [CrossRef] [PubMed]

(C) 2019 by the authors. Licensee MDPI, Basel, Switzerland. This article is an open access article distributed under the terms and conditions of the Creative Commons Attribution (CC BY) license (http://creativecommons.org/licenses/by/4.0/). 